\title{
Morphology Numeric Result in Standard Unit
}

National Cancer Institute

\section{Source}

National Cancer Institute. Morphology Numeric Result in Standard Unit. NCI Thesaurus.

Code C117614.

The numerical identifier of morphology result in standard units. 